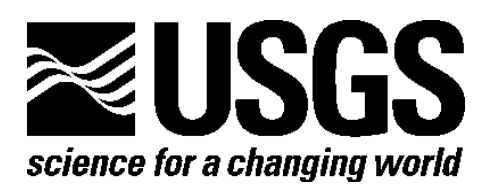

\title{
Developing an Institutional Framework to Incorporate Ecosystem Services into Decision Making-Proceedings of a Workshop
}

By Dianna Hogan, Greg Arthaud, David Brookshire, Tom Gunther, Stephanie Pincetl, Carl Shapiro, and Bea Van Horne

Open-File Report 2011-1221

U.S. Department of the Interior

U.S. Geological Survey 


\section{U.S. Department of the Interior \\ KEN SALAZAR, Secretary}

\section{U.S. Geological Survey \\ Marcia K. McNutt, Director}

U.S. Geological Survey, Reston, Virginia: 2011

For more information on the USGS—-the Federal source for science about the Earth, its natural and living resources, natural hazards, and the environment-visit

http://www.usgs.gov or call 1-888-ASK-USGS

For an overview of USGS information products, including maps, imagery, and publications, visit http://www.usgs.gov/pubprod

To order this and other USGS information products, visit http://store.usgs.gov

Suggested citation:

Hogan, Dianna, Arthaud, Greg, Brookshire, David, Gunther, Tom, Pincetl, Stephanie, Shapiro, Carl, and Van Horne, Bea, 2011, Developing an institutional framework to incorporate ecosystem services into decision making-Proceedings of a workshop: U.S. Geological Survey Open-File Report 2011-1221, 9 p. Available at http://pubs.usgs.gov/of/2011/1221.

Any use of trade, product, or firm names is for descriptive purposes only and does not imply endorsement by the U.S. Government.

Although this report is in the public domain, permission must be secured from the individual copyright owners to reproduce any copyrighted material contained within this report. 


\section{Contents}

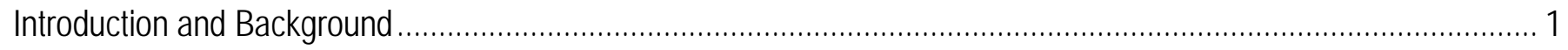

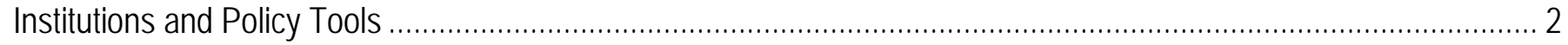

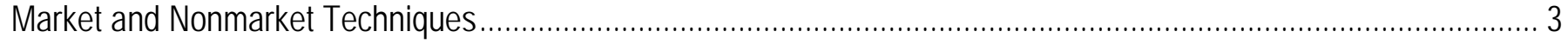

Considerations for the Scientific Evaluation of Ecosystem Services................................................................... 4

Considerations for Implementing Ecosystem Services Regulation, Mitigation, and Management .............................. 5

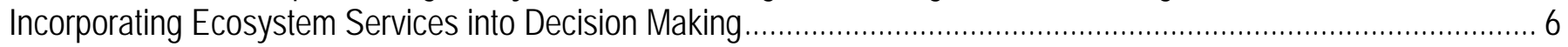

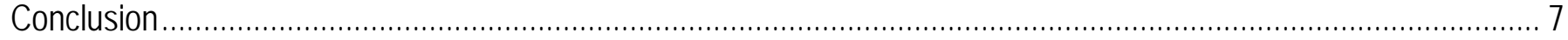

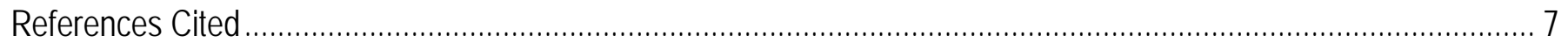

Appendix 1. Participants in Preconference Workshop 3, Developing an Institutional Framework to Incorporate

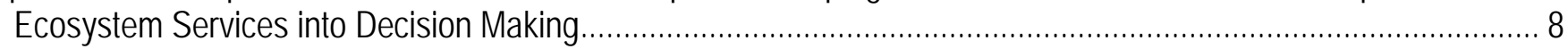




\section{Developing an Institutional Framework to Incorporate Ecosystem Services into Decision Making-Proceedings of a Workshop}

By Dianna Hogan, ${ }^{1}$ Greg Arthaud, ${ }^{2}$ David Brookshire,${ }^{3}$ Tom Gunther, ${ }^{1}$ Stephanie Pincetl, ${ }^{4}$ Carl Shapiro, ${ }^{1}$ and Bea Van Horne ${ }^{1}$

This workshop was hosted by the Science Impact Laboratory for Policy and Economics (SILPE) University of New Mexico, Albuquerque, NM

October 30, 2008

In association with

A Conference on Ecosystem Services (ACES)

ACES 2008: Using Science for Decision Making in Dynamic Systems

\section{Introduction and Background}

The routine and effective incorporation of ecosystem services information into resource management decisions requires a careful consideration of the value of goods and services provided by natural systems. A multidisciplinary workshop was held in October 2008 on "Developing an Institutional Framework to Incorporate Ecosystem Services into Decision Making.” This report ${ }^{5}$ summarizes that workshop, which focused on examining the relationship between an institutional framework and consideration of ecosystem services in resource management decision making.

This workshop was the third in a series of three preconference workshops associated with ACES 2008 (A Conference on Ecosystem Services): Using Science for Decision Making in Dynamic Systems. These workshops were designed to explore the ACES 2008 theme on decision making and how the concept of ecosystem services can more effectively be incorporated into conservation, restoration, resource management, and development decisions. Preconference workshop 1, "Developing a Vision: Incorporating Ecosystem Services into Decision Making,” was held April 15, 2008, in Cambridge, MA. In this workshop, participants addressed what would have to happen to make ecosystem services more routinely and effectively used in conservation, restoration, resource management, and development decisions, and identified some key challenges to developing the analytical framework (Hogan and others, 2009). Preconference workshop 2, "Developing an Analytical Framework: Incorporating Ecosystem Services into Decision Making," was held July 28, 2008, in Naples, FL, and focused on the

\footnotetext{
${ }^{1}$ U.S. Geological Survey, Reston, VA.

${ }^{2}$ U.S. Forest Service, Washington, DC.

${ }^{3}$ University of New Mexico, Albuquerque, NM.

${ }^{4}$ U.S. Forest Service, Pacific SW Research Station, Riverside, CA; UCLA Institute of the Environment, Los Angeles, CA

${ }^{5}$ The ideas presented in this report are based on contributions from participants at the workshop. Workshop participants are listed in appendix 1.
} 
analytical process and identification of research priorities for ecosystem services, their production and use, their spatial and temporal characteristics, their relationship with natural systems, and their interdependencies (Hogan and others, 2010). The summary presented here synthesizes the discussion at workshop 3 and considers how institutional structures and policy instruments can be used to achieve the vision developed in workshop 1, while recognizing the analytical capabilities and limitations identified in workshop 2.

Our purpose was to identify how to use ecosystem service information more effectively and broadly in resource management and development decisions. We recognized the need to facilitate an integrated understanding of (1) the natural capital that produces ecosystem services; (2) the geospatial and temporal aspects of ecosystem service production, values, and use; (3) the value of ecosystem services (monetary and nonmonetary); and (4) institutional instruments, processes, and structures (property rights, laws, governance structures, and courts, for example). Interdisciplinary collaboration and understanding is beneficial and needs to engage stakeholders.

The appropriate use of institutional structures, including markets, to integrate ecosystem services into decision making depends on the players and characteristics of the specific situation (such as stakeholders, the ecosystem, resources, and the political environment). Incorporating ecosystem service values into decisions requires consideration of place-based social, cultural, economic, and landscape characteristics and institutions. Thus, a single, prescribed solution will not work-various institutional strategies must be used in different situations. Market-based approaches require appropriate regulations, monitoring, and enforcement, depending on the situation and place. Further, market approaches will need to be coupled with nonmarket approaches into an integrated institutional framework.

\section{Institutions and Policy Tools}

Institutions can change to better recognize the value of ecosystem services and to incorporate those values in resource management decisions. Incorporating ecosystem services into decision making will involve a wide array of institutions and policy tools including regulations, taxes, incentives, markets, subsidies, and property rights delineation. These tools can be used to influence economic and social behavior to be consistent with environmental and other policy goals. Better geographic, ecological, and economic accounting of natural capital and resulting ecosystem services will be required for this effort.

Institutions will need to formulate and implement policies and develop structures that enable decision makers to consider ecosystem services in decision making more effectively. Institutions that would be affected by consideration of ecosystem services in decision making include:

- Institutions with direct interest in or control of natural resources. These institutions typically have goals of resource protection or allocation and can impose or reduce market constraints.

- Institutions with direct interest in or control of markets. The goals of these institutions are monetary and (or) distributional and are market oriented.

- Political institutions that express nonmarket values of affected populations, such as resource conservation, economic development, and social and cultural aspects.

An increasingly important role of government (Federal, State, and local) is to provide unbiased data and information on the quantity, production, value, and location of ecosystem services and to facilitate stakeholder participation in management, preservation, and restoration decisions. The Federal Government has recognized the need for ecosystem service measurement standards and a registry through the development of the cabinet-level Conservation and Land Management Environmental Services Board (http://www.fs.fed.us/ecosystemservices/pdf/farmbill/ESB_Charter.pdf). Many 
ecosystem services can reasonably be assigned economic value, but some cannot. Some of the most fundamental and challenging aspects of ecosystem services (for example, long-term resilience, ecosystem sustainability, and cultural sustainability) may or may not be quantifiable.

The Federal Government, the largest land manager in the United States, has a substantial influence on the use of ecosystem services (for example, use of permits for resource extractions such as oil or gas on Bureau of Land Management lands). Further, Federal agencies have a range of tools (rules, regulations, taxes, and other incentives) to encourage the sustainable use of ecosystem services.

Decision makers at Federal, State, tribal, and local jurisdictions as well as private landowners will need to be included.

The role of nongovernmental organizations (NGOs), academia, and the public and private sectors will vary depending on the ecosystem service(s) in question, the institutional structure in place, and the availability of ecological, economic, and geospatial information. The differences in goals, objectives, rewards, and disincentives between various types of research entities (academia, government, NGOs, and others) and decision makers (both public and private) can create conflicts for the process, timeliness, confidence in conclusions, and implementation. Including different stakeholders and institutions may, however, enhance the incorporation of ecosystem services into decision making.

Many ecosystem services have characteristics that benefit the public good; these characteristics can pose policy challenges when the ecosystem services are generated on private lands. Legal tools for the private sector may include regulations, taxes, and other incentives, or the creation of markets, including the right to create habitat and sell credits. Regulations to protect service values are useful when, for the public good, services need to be maintained at a certain level by private landowners. Markets can be used across an area in which the particular location within that area that produces a certain level of service is not important. Private landowners that generate services may look to government(s) to help create ecosystem service markets. However, the public may react negatively to paying for services that previously were free. Incentives are most useful when there is no strong minimal threshold value for a service but where value to users of the service is an increasing function of the amount of service available - that is, there is no danger of saturation. The use of an instrument may depend on land ownership; for instance, incentives may be appropriate for private lands, but may not be for public lands.

Culture, beliefs, knowledge, and experiences influence behavior. Environmental value is in many ways socially constructed and mediated by these influences. Understanding how stakeholders define their role in the environment is important to bringing the consideration of ecosystem services into decision making.

\section{Market and Nonmarket Techniques}

Our focus is on the use of markets and other institutional approaches for facilitating the consideration of ecosystem services in decision making. Identifying the location, quantities, values, and production processes of ecosystem services is a prerequisite to creating the markets and other institutional structures necessary for their allocation.

Creating new markets for ecosystem services will affect land use and management and requires improved landscape information, including detailed ecosystem and land use maps. New markets require an understanding of inputs and outputs from combinations of ecosystems and land use, and perhaps most importantly, an awareness of how ecosystems may be affected by a variety of anthropogenic and climatic futures. We also need to be aware that adding new markets may have both positive and negative implications, depending on what is included and what is left out. 
Ecosystem services markets and other institutional approaches may require information including (1) interdisciplinary knowledge, including integrated hydrologic, engineering, physical science, biological, institutional, behavioral, and economic models; (2) defined, securable and tradable property rights; (3) reasonable transaction costs; (4) demand and production functions; and (5) consideration of third party effects. Natural and social science information plays a critical role in designing and driving ecosystem services markets because both inform the valuation process.

An understanding of when changes in ecosystem services are likely to occur (for example, ecological tipping points) is also important. Goals for ecosystem services based on knowledge of change may be used to prevent or constrain the market, or the ecosystem service(s) may be assigned a trustee (for example, allocate water rights to an ecosystem trustee who is allowed to participate in market transactions) to maintain the ecosystem services at some level.

The existence of well-functioning, transparent markets may create financial incentives for landowners to create and sell environmental credits, and may encourage a greater number of private sector conservation actions. This may result in the restoration of degraded habitats more rapidly and efficiently, may conserve quality habitats that are currently likely to be developed, and could help provide increased protection of contiguous, quality habitat.

For a market exchange process to fully incorporate ecosystem values into decision making, nonmarket values must also be considered. This may be done by placing further constraints on the market or by including institutions that represent the non-market values in the market. Limiting ecosystem service value debates exclusively to monetary measures may cause substantial loss of information and resources.

Regulatory tools may be used in conjunction with market mechanisms. Resource banks for wetlands, grasslands, wildlife habitat, and other similar areas include credits as financial incentives for those who improve the condition of ecosystem services. These credits could be monetary, or could represent a given level of ecological services per acre (for example, service/acres/year), and would be granted within the regulatory process. This can enhance the value of ecosystem services or make them more available, or can require payment for the loss of services according to ecosystem status, service values (timing, location, distance to threshold), and (or) by comparison to reference sites (like wilderness areas). Bank credits are supplied by habitat restoration, improvement, preservation, or protection activities. Demand for credits is often generated by legal impact minimization or mitigation responsibilities and is subject to regulation linked to habitat type, the situation, and the expected performance of the mitigation action.

With respect to the use of resource banks and trades, it is important to consider the location of the mitigation and the development it offsets to avoid trading a resource out of the native place where it belongs (such as South America versus effects in North America) and to ensure that trading benefits the desired stakeholders and ecosystem(s) without harming others. Markets can be adjusted to satisfy different requirements (for example, disallow interbasin transfers of water). Markets can be initiated by a government entity serving as the dominant buyer, or they can be initiated by private entities.

\section{Considerations for the Scientific Evaluation of Ecosystem Services}

Scale.-Ecosystem services are multiscalar and their value varies with the geographic and temporal scale at which they are assessed. Multiscale evaluations offer a more comprehensive identification and analysis of ecosystem services from source to users.

Indicators.-Ideally, the indicators of the extent and condition of ecosystem services need to be useful, small but sufficient in number, and easy and cost-effective to measure accurately. They should be developed with a clear knowledge of what they indicate and how they will be used, and how well 
indicator patterns correspond to what they are indicative of. In addition, indicators need to be sensitive to incremental effects, include socioeconomic and cultural values, and be able to identify and track tradeoffs and secondary effects of management actions.

Model and data integration.--Models for measuring and valuing ecosystem services need to do a better job of forecasting changes in both supply and demand under alternative management scenarios in light of demographic, climate, land use, and other changes.

Tradeoffs.-Management, more often than not, involves complex tradeoffs between and within the quantity and quality of different ecosystem services. For example, a forest may play a role in water supply regulation, water filtration, carbon sequestration, and wood products provision. Not all of these can be optimized simultaneously. More modeling capacity is needed to develop spatially explicit models that can be used to explore the effects of management actions on multiple ecosystem services.

Understanding one ecosystem service may require considering and assessing it in the context of other ecosystem services.

\section{Considerations for Implementing Ecosystem Services Regulation, Mitigation, and Management}

Issue: Information needed to facilitate consideration of ecosystem services in decision making is difficult to identify and gather. For markets, readily available information on monitoring, assessment, location, prices, availability, and conveyance of ecosystem services is essential for both buyers and sellers.

Solution: Our understanding of the spatial distribution, quantities, values, and biophysical production processes of ecosystem services is improving, but we need to identify the most important information needed to facilitate consideration of ecosystem services in decision making. Federal regulatory agencies with responsibility for ecosystem services should be clearly identified, and monitoring plans should be developed to adequately characterize the status and trends in ecosystem services, explore patterns of change, understand causal mechanisms, and look for associations with management and natural drivers.

Example: Several demonstration (place-based) studies are being implemented to provide information on key methods and data to help generate better maps and models of ecosystem services production for use by decision makers. Although the many areas and conditions require different approaches, knowledge gained in one area can be used to inform studies in another area.

Issue: Structural market incentives may undermine ecosystem valuation efforts. For example, land close to urbanizing areas often has higher development value than land further from urban centers. Compensating land owners to maintain their ecosystem services closer to urban centers may not be sufficient to counteract the increase in market value for development.

Solution: Structural market incentives need to be identified and the economic, social, and environmental tradeoffs should be considered.

Issue: Management actions may inadvertently damage ecosystem services in areas adjacent, downstream, downwind, or simply outside of the action area.

Solution: Mitigation could be used to improve ecosystem services for the people whose services are damaged by management actions. Regulations could consider geographic areas of effect for damage to ecosystem services and for mitigation activities.

Issue: Many ecosystem services are provided and consumed as common property resources (for example, natural flood control, water filtration, carbon sequestration, and pollination). As a result, too few services may be produced relative to demand. 
Solution: Regulating common property resources may be accomplished more easily by a group that is small enough to communicate easily and has the right to monitor and sanction actions. In addition, fostering a sense of place and ownership brings forth awareness, understanding, and public participation.

Example: Degraded water quality in the Chesapeake Bay is a cumulative result of the actions taken by numerous property owners in the watershed (such as private homeowners fertilizing lawns and gardens). Monitoring the effect of watershed management actions on Chesapeake Bay water quality and developing incentives may improve participation in cleanup efforts.

Issue: In some cases, ecosystem services could be better protected if property rights were clear and enforceable. However, where property owners have clear rights, stakeholders may feel disconnected from the services their land produces.

Solution: Use a shared responsibility governance approach with stakeholders and residents participating as local landscape stewards.

Example: Using metrics of ecological integrity, aesthetics, quality of life, and a sense of place connects both landowners and other stakeholders to stewardship activities across the landscape.

Issue: Understanding one ecosystem service may require considering and assessing it in the context of other ecosystem services. There can be complex tradeoffs between different ecosystem services that need to be recognized in management decisions.

Solution: Develop new, spatially explicit models that can be used to explore the effects on multiple ecosystem services of management actions, scale, and interconnectedness.

Example: A forest may play a role in water supply regulation, water filtration, and wood products provision. Not all of these services can be optimized simultaneously.

Issue: Many people do not fully understand the various aspects of ecosystem services such as how clean water is supplied, the importance of pollinators, and how land use contributes to carbon sequestration. Improving communication of the existence and importance of ecosystem services would enhance the understanding of their value.

Solution: Collaborate with communication specialists to communicate the existence and importance of these services.

Issue: The cultural context of ecosystem services is often not fully understood or appreciated. For example, prairie dogs provide burrows that are important for maintaining biodiversity and soil health in some regions. Landowners may find the presence of these burrows "messy" or indicative of lazy or poor agricultural practices.

Solution: A successful program must account for what is important to stakeholders.

\section{Incorporating Ecosystem Services into Decision Making}

Research in the following areas will support improvements to incorporating ecosystem services in decision making.

- Develop a better understanding of (1) the role of ecosystem processes in producing ecosystem services, and (2) the influence of external drivers in the production of services.

- Develop better decision support tools. Reaching the goal of valuing and incorporating ecosystem services into decision making requires considering tradeoffs and making informed and balanced decisions. Markets, regulation, taxation, research, and incentives can be complimentary and interrelated tools, but communication, transparency, and education are paramount. Decision makers need the data, tools, and understanding to help them consider a combination of objectives. Decision support tools should be able to bridge communication gaps and promote transparency to provide a platform for rapid scenario screening, to educate and engage the public 
and decision makers in decision making and planning, and to provide a framework for integrated analysis of the diverse concepts and tradeoffs associated with different scenarios.

- Improve monitoring in an adaptive management framework. Adaptive management is an iterative process of objective setting, monitoring, assessment, learning, and adapting based on what is learned, with the goal of improved understanding and management. Adaptive management techniques should be used to systematically test the efficacy of methods for mapping, assessing, and valuing ecosystem services in different regions to improve the tools and provide feedback on the effectiveness of alternative institutional structures, managed approaches and policies. By incorporating rigorous monitoring, adaptive management can expedite the learning process and reduce uncertainty. Guidelines for the use of different instruments such as payments, regulation, taxation, property rights, incentives, protection, or voluntary selfregulating behavior are needed.

\section{Conclusion}

Incorporating ecosystem services into decision making requires a variety of institutional approaches and structures that apply a combination of instruments. Pilot studies provide an opportunity to experiment with some alternative instruments. Candidate pilot prototype areas include the Rio Grande, Colorado River, San Pedro, Greater Everglades, Puget Sound, Great Basin, San Francisco Bay Delta, Mojave Desert, Southern California, Greater Yellowstone, Platte River, Prairie Potholes, Lower Mississippi Valley, Chesapeake Bay and watershed, Arid and semiarid lands, Bays and estuaries, and Midcontinent. These areas have developed substantial interdisciplinary datasets describing ecosystem condition, but only a few of them to date have focused directly on the production and analysis of ecosystem services.

Different approaches will be needed in differing situations to address diverse issues, goals, and stakeholder preferences. The use of place-based studies and demonstration areas is important to improving understanding and to testing techniques and analytical tools. Protection or restoration activities followed up with monitoring and assessment in an adaptive management framework will play a key role in improving our understanding and management capabilities and in developing new measurement tools and institutional arrangements. Finally, research is needed to link ecosystem change in structure, function, and processes to changes in ecosystem services and their values.

\section{References Cited}

Hogan, Dianna, Arthaud, Greg, Goodman, Iris, Pattison, Malka, Sayre, Roger, Shapiro, Carl, and Van Horne, Bea, 2009, Developing a vision-Incorporating ecosystem services into decision making; Proceedings of a workshop: U.S. Geological Survey Open-File Report 2009-1062, 8 p., available online at http://pubs.usgs.gov/of/2009/1062/.

Hogan, Dianna, Arthaud, Greg, Pattison, Malka, Sayre, Roger, and Shapiro, Carl, 2010, Developing an analytical framework-Incorporating ecosystem services into decision making; Proceedings of a workshop: U.S. Geological Survey Open-File Report 2009-1259, 6 p., available online at http://pubs.usgs.gov/of/2009/1259/. 


\section{Appendix 1. Participants in Preconference Workshop 3, Developing an Institutional Framework to Incorporate Ecosystem Services into Decision Making}

Cyndie Abeyta, Middle Rio Grande Coordinator/Hydrologist, USFWS, Albuquerque, NM

Greg Arthaud, Acting National Program Leader: Economics Research, USFS, Washington, DC

Craig Broadbent, graduate student, University of New Mexico, Albuquerque, NM

David Brookshire, Professor and Director of Science Impact Laboratory for Policy and Economics, University of New Mexico, Albuquerque, NM

Tom Brown, Economist, USFS Rocky Mountain Research Station, Fort Collins, $\mathrm{CO}$

Iris Goodman, Acting Deputy National Program Director for Ecology, EPA, Washington, DC

Dave Goodrich, Research Hydraulic Engineer, ARS, Tucson, AZ

Tom Gunther, Program Coordinator, USGS Enterprise Information, and Project Lead for Data Integration and Interoperability, USGS, Reston, VA

Tim Hayden, Program Manager, U.S. Army Corps of Engineers, Champaign, IL

Jim Henderson, Program Manager, U.S. Army Engineers Research and Development Center, USACE, Vicksburg, MS
Dianna Hogan, Research Physical Scientist, Eastern Geographic Science Center, USGS, Reston, VA

Bea Van Horne, Ecosystem Program

Coordinator, USGS, Reston, VA

Ron Huntsinger, National Science

Coordinator, BLM, Washington, DC

Malka Pattison, Program Analyst, Office of Policy Analysis, DOI, Washington, DC

Edwin Pfeifer, Chief, USGS Southwest Geographic Science Team, USGS, Tucson, AZ

Stephanie Princetl, USFS, Riverside, CA; UCLA, Institute of the Environment, Los Angeles, CA

Carol Raish, Anthropologist, USFS Rocky Mountain Research Station, Fort Collins, $\mathrm{CO}$

Deanna Reynolds, USGS, Sioux Falls, SD (Workshop Facilitator)

Darius Semmens, Research Physical Scientist, Rocky Mountain Geographic Science Center, USGS, Denver, CO

Carl Shapiro, Senior Advisor, Geography

Discipline, USGS, Reston, VA

Benjamin Simon, Economist, Acting Assistant Director, Office of Policy Analysis, DOI, Washington, DC Jennifer Thatcher, University of New Mexico, Albuquerque, NM 
Vince Tidwell, Hydrologist, Sandia National

Laboratory, Albuquerque, NM

Ken Williams, Biological Resources

Division, USGS, Reston, VA

Rob Winthrop, Senior Social Scientist,

BLM, Washington, DC 